https://helda.helsinki.fi

\title{
Application of NIR imaging to the study of expanded snacks containing amaranth, quinoa and kañiwa
}

\section{Ramos Diaz, Jose Martin}

2019-03

Ramos Diaz, J M , Rinnan, Å \& Jouppila , K L 2019 , ' Application of NIR imaging to the study of expanded snacks containing amaranth, quinoa and kañiwa ' , LWT-Food Science and Technology , vol. 102 , pp. 8-14 . https://doi.org/10.1016/j.lwt.2018.12.029

http://hdl.handle.net/10138/312554

https://doi.org/10.1016/j.Iwt.2018.12.029

cc_by_nc_nd

acceptedVersion

Downloaded from Helda, University of Helsinki institutional repository.

This is an electronic reprint of the original article.

This reprint may differ from the original in pagination and typographic detail.

Please cite the original version. 
1 APPLICATION OF NIR IMAGING TO THE STUDY OF EXPANDED SNACKS

2 CONTAINING AMARANTH, QUINOA AND KAÑIWA

3

4 Jose Martin Ramos-Diaz ${ }^{1}$, Åsmund Rinnan ${ }^{2}$, Kirsi Jouppila $^{1}$

$5 \quad{ }^{1}$ Department of Food and Nutrition, P.O. Box 66 (Agnes Sjöbergin katu 2) FI-00014 University of

6 Helsinki, Finland

$7 \quad{ }^{2}$ Department of Food Science, Chemometrics and Analytical Technology, Rolighedsvej 26, DK-

8 1958, University of Copenhagen, Denmark

9

$10 *$ Corresponding author. Jose Martin Ramos Diaz, P.O. Box 66 (Agnes Sjöbergin katu 2) FI-00014

11 University of Helsinki, Finland. E-mail: jose.ramosdiaz@ helsinki.fi. Tel. 358504485951 . Fax.

$12+358294158460$

13

14

15

16

17

18

19

20 


\section{ABBREVIATONS}

22 IJ: The complete image that was measured

$23 \quad K$ : Number of measured wavelengths

$24 \quad \mathbf{M}_{\mathrm{i}}$ : The image mask for sample $i$

$25 \quad N$ : Sample number

$26 N_{i}$ : Number of pixels (excluding background) for sample $i$

27 NIR: Near infrared

$28 N_{\text {tot }}$ : The number of pixels in all samples in total

29 P: Loadings from the PCA on the unfolded NIR images

30 PLS: Partial Least Squares regression model

T: Scores from the PCA on the unfolded NIR images

TDS: Temporal dominance of sensation 20/35/50K: Corn-based extruded samples containing 20, 35 or 50\% kañiwa of solids 20/35/50Q: Corn-based extruded samples containing 20, 35 or 50\% quinoa of solids 50/80C: Extruded samples containing 50 and $80 \%$ corn of solids 
Amaranth (Amarantus caudatus), quinoa (Chenopodium quinoa) and kañiwa (Chenopodium

43

44

45

46

47

48

49

50

51

52

53

54

7 9 60 pallidicaule) are Andean grains that are gaining interest as nutritious gluten-free alternatives to conventional cereals. Near infrared (NIR) imaging was applied to extrudates containing 20,35\% and $50 \%$ amaranth, quinoa and kañiwa in order to study the spatial distribution of fibre and protein along the cross-sectional area. The results were contrasted with existing physical measurements (e.g., sectional expansion, stiffness) and textural data obtained from sensory profiling and temporal studies (i.e., temporal dominance of sensation, TDS). Score distribution in PCA plots was directly associated to fibre (PC1) and protein (PC2) due to spectral wavelength specificity (fibre: 1028nm; protein: 1470 nm). Partial Least Squares regression model (PLS) showed that evenly distributed protein structures are strongly linked to desirable TDS textural properties such as crispiness and crunchiness, while protein clumps were linked to undesirable properties such as roughness. In contrast, fibre was found to reduce roughness. PLS could not explain accurately changes in physical attributes, and sensory data from profiling tests had to be omitted from computing due to lack of fit. This study shows that NIR hyperspectra imaging could help elucidate the chemical background of physical and particularly temporal dominant attributes. 


\section{INTRODUCTION}

Amaranth (Amarantus caudatus), quinoa (Chenopodium quinoa) and kañiwa (Chenopodium pallidicaule) are grains traditionally cultivated in the Andes of South America in areas around or above 4000 m.a.s.l. Over the years, quinoa has also been successfully cultivated in USA, UK, Denmark, The Netherlands, Finland and India (Janick et al., 1996; Jacobsen, 2003; Bhargava et al., 2006). According to FAO (2011), quinoa along with amaranth are promising foods for the future due to their outstanding nutritional characteristics (e.g. protein quality, high content of fibre). Although kañiwa is a much lesser known grain, its nutritonal qualities are similar to those of quinoa and amaranth, and the production of kañiwa-containing extruded snacks is on the rise (Ramos Diaz, 2015). Extrusion is a versatile technology that alters the physicochemical characteristics of grain flours, containing starch and protein, through increasing pressure and temperature along the extruder barrel (Ramos Diaz, 2015; Ramos Diaz et al., 2015b). The resulting snack is expected to have an expanded, porous structure, and crispy texture upon mastication.

According to Bressani and Garcia Vela (1990), the two largest protein fractions in amaranth are globular proteins (albumins and globulins) and glutelins, accounting for around 90\%, while the prolamine fraction is below $5 \%$. In contrast, quinoa was found to have up to $27 \%$ prolamines, and fractions of globular proteins and glutelins accounting for around 70\% (Scarpati de Briceño, 1979; Scarpati de Briceño and Briceño, 1980). In kañiwa, prolamine accounted for around one third of the proteins (Scarpati de Briceño, 1979). Regarding starch, quinoa seems to contain more amylose than amaranth (around 12 and 7\%, respectively) (Stone and Lorenz, 1984; Lorenz 1990; Qian and Khun, 1999; Jane et al., 1994; Lindeboom, 2005; Kong et al., 2009). To the best of our knowledge, there is no information on amylose/amylopectin ratio of kañiwa. Upon extrusion, low content of amylose is associated to highly elastic doughs leading up to greater expansion (and potential shrinkage) of extrudates at die point (Babin et al., 2007; Ramos Diaz 2015). 
Various studies (Ilo and Lui, 1999; Ramos Diaz et al., 2013; Ramos Diaz, 2015) have observed that increasing contents of protein or fibre, and the addition of water into the system descrease the sectional expansion of extruded snacks. Conversely, low content of amylose has been associated to highly elastic doughs upon extrusion, bringing about greater expansion and potential shrinkage of extruded snacks at die point (Babin et al., 2007; Ramos Diaz 2015). Despite this, little is known about the spatial distribution of food component (e.g. protein, starch) across the sectional area, and the potential effect this may have on the physical and textural characteristics of the product. In that regard, near infrared (NIR) hyperspectral imaging is an optical nondestructive method that allow us to explore the distribution of food components. NIR is based on the molecular capacity to attenuate light at a given wavelength $(700-2500 \mathrm{~nm})$ or, technically called, molar absorptivity. This is associated to a degree of molecular excitation that is specific to particular chemical groups such as hydroxyls and amines. The overtone bands or molecular overtones (specific to chemical groups) are then observable in the NIR spectra.

Although this optical multispectral meaurement is nondestructive, fast to conduct and ideal for online monitoring, it is not as specific as chemical tests, and requires a great deal of data analysis (e.g. pre-processing, modelling) prior to interpretation. However, it gives a good overview of the sample measured with only one analysis. The amount of information largely surpass that of any of the chemical tests, and can lead to new understanding of the system at hand. According to Alander et al. (2013), the mathematical models created, very often, cannot be generalised, and need to be adjusted to new conditions. Although this may be seen as a weakness, this is also a strength, indicating that NIR is capable to detect even minor changes in the sample matrix. Furthermore, the problem mentioned by Alander et al. (2013) also indicates another strength of spectroscopy coupled with chemometrics; they inheret the first-order advantage (Booksh and Kowalski 1994), meaning that it will indicate to the user when a change in the sample matrix for new samples has occurred. This is not possible with the regular chemical tests as these are univariate by nature. 
113 The aim of this study is to identify the spatial location of major food components in extrudates containing amaranth, quinoa and kañiwa through the application of NIR hyperspectra imaging, and study the effect of such food components on specific sensory attributes through the application of chemometrics.

\section{MATERIAL AND METHODS}

\section{Materials}

Commercial varieties of amaranth, quinoa and kañiwa were purchased from South America as seeds (Aduki Ltd., Finland), and milled with a pin disc grinding device (100 UPZ-lb, Hosokawa Alpine, Augsburg, Germany) at the Technical Research Centre of Finland (VTT). Pregelatinised corn flour (Polenta flour, Risenta AB, Sweden) was obtained from a local store in Helsinki, Finland. The calculated composition of flour blends is shown in Table 1. The median particle sizes of amaranth, quinoa, kañiwa and corn flour were 285, 575, 240 and $747 \mu \mathrm{m}$, respectively. Particle size was determined by laser light diffraction in a Beckman Coulter LS230 particle size analyser (Coulter Corporation, Miami, USA). Samples were first dispersed in 95\% ethanol using magnetic stirring, and then incubated in an ultrasound bath $(5 \mathrm{~min})$ to prevent the formation of aggregates. The volumetric distribution of the particles (in accordance with the Fraunhofer diffraction model and geometric statistics) was used to calculate medians of the particle sizes.

\section{Extrusion}

Extrudates were prepared using a co-rotating twin-screw extruder (Thermo Prism PTW24, Thermo Haake, Germany). The extruder consisted of seven sections with individual temperature control in six of them (each $96 \mathrm{~mm}$ in length). The feed rate was maintained at $86 \mathrm{~g} / \mathrm{min}$ (constant) and the temperature profile was fixed at $90{ }^{\circ} \mathrm{C}$ (section 1), $95{ }^{\circ} \mathrm{C}$ (section 2$), 95{ }^{\circ} \mathrm{C}$ (section 3$), 100{ }^{\circ} \mathrm{C}$ (section 4), $110^{\circ} \mathrm{C}$ (section 5) and $140{ }^{\circ} \mathrm{C}$ (section 6). Further details on the extrusion conditions 
can be found in Ramos Diaz et al. (2015). The samples used in the present study were obtained under the following conditions: a. Content of amaranth, quinoa or kañiwa, 20, 35\% and 50\% (of solids); b. Water content of mass, $14 \%$; c. Screw speed, $500 \mathrm{rpm}$; d. Temperature of die, $140{ }^{\circ} \mathrm{C}$.

\section{Physical and sensory evaluation}

Sectional expansion index (SEI) was the ratio between the cross-sectional area of an extrudate and die. Stiffness was calculated as the slope of force-formation curve in a universal testing machine (Instron 4465, Instron Ltd., High Wycombe, UK) under three-point bending conditions. Extrudates were positioned perpendicularly over a sample holder (12-mm gap) and the speed of the aluminium probe was $5 \mathrm{~mm} / \mathrm{min}$ (Ramos-Diaz 2015). Water absorption index (WAI) and water solubility index (WSI) was calculated following the method described by Mäkilä et al. (2014).

Regarding the sensory evaluation, panellists ( $\mathrm{n}=10$, aged 20-30 years) were in trained in English for up to 12 hours at the sensory laboratory of the Department of Food and Nutritional Sciences of the University of Helsinki. Sensory profiling; training was performed to familiarize the panel with extrudates and develop a set of descriptors, references and definitions. Panellists were first introduced to various commercial extruded products in order to generate a preliminary list of attributes linked to texture. Reference samples are described by Ramos-Diaz et al. (2015). Each panellist evaluated all 9 samples [three contents of flours $(20,35,50 \%) \times$ three grain types (amaranth, quinoa, kañiwa)] in duplicate. The intensity of the descriptors on unstructured 10-cm line scales with the anchors: "not at all" and "very". The attributes for texture were: crispiness, crunchiness (not included in the present study), hardness, hard particles and adhesiveness. Temporal dominance of sensation (TDS); Panellists discussed and generated a set of descriptors associated to dominant perceptions during mastication. The list of potentially dominant descriptors was presented in this order (decided by consensus): crispiness, hardness, crunchiness, roughness, stickiness and gooeyness. Panellists began the evaluation by placing the sample in their mouth and then selecting the descriptor they perceived as 
163

dominant. As the time went by, panellists evaluated changes in dominant descriptors upon mastication (e.g. from crispiness to crunchiness). The order of change and the time of dominance was registered and subsequently analyzed.

For either sensory profiling or TDS test, data management was carried out with FIZZ Sensory Evaluation Software, Version 2.45 (Biosystemes, Courternon, France).

\section{NIR measurements}

Extrudates were dehydrated for three days at $52{ }^{\circ} \mathrm{C}$ in vacuum incubator prior to packaging in modified atmosphere $\left(\mathrm{N}_{2}\right)$. These samples were eventually sliced in to pieces of $5 \mathrm{~mm}$ in height before NIR measurement. The NIR-hyperspectral images were obtained with a spectrometer (Headwall Photonics, Model 1002A-00371, Fitchburg, MA) working in a wavelength range of 1000-1700 nm with a spectral resolution of $7 \mathrm{~nm}$. In total, 142 wavelength bands were recorded for each pixel. The measurement was conducted on nine replicates per extrudate sample. Thus, a total of 81 images were recorded (9 replicates $\times 3$ grain types $\times 3$ contents), however, due to an error for one of the measurements, one of the images (one image with 20Q) could not be retrieved from the camera, reducing the total number of images to 80 . The number of pixels for each image was on average 185 x 56.

\section{Data handling}

Each step in the data handling is shown in Figure 1.

i. The background for each of the images (Figure 1A) were removed by making a mask indicating whether a pixel in the image contained the extrudate (1) or the background (0) (Figure 1B).

ii. The mask was then applied to each image (Figure 1C). 
iii. Subsequently each image was unfolded, creating a matrix of size IJ x 142 columns (one row per pixel and one column per NIR wavelength; Figure 1D).

iv. All samples were concatenated, giving rise to a matrix containing $N$ x $I J$ rows and 142 columns (Figure 1E). $N$ equals the total number of images, which were 80, and $I J$ indicates the number of extrudate pixels for each image. However, due to a lighting problem for one of the remaining images (one image with 20Q, probably related to the missing image mentioned above), an outlier was spotted in a preliminary PCA, thus reducing the number of images further to 79 . The total number of spectra thus ended up being 520.062 .

v. Each row of this matrix was pre-processed (Figure 1F) by first smoothing the spectra according to the Savitzky-Golay algorithm (Savitzky-Golay, 1964) using a window size of nine, 2nd order polynomial for fitting the data and exclusion of the end-points. This was important in order to improve the signal-to-noise-ratio of the spectra. In order to reduce the scattering effects, all data were subsequently pre-processed by Multiplicative Scatter Correction (MSC; Geladi et al., 1985).

vi. For each image, the average spectrum was extracted, and a global PCA (Figure 1G) was made on these 79 spectra by 134 wavelengths (the four first and four last wavelengths were lost during the Savitzky-Golay pre-processing step). The pixels for all the images were subsequently projected onto this PCA model. Please note that both the reference for the MSC and the average spectrum used for the mean-centering were calculated based on the 79 average spectra.6. In order to visualize the PCA, the calculated scores were refolded back into the shape of the original image (Figure 1H). 
213 In order to compare the NIR image data and the sensory evaluations, a PLS analysis was conducted 214 with the average spectra of each sample type (quinoa, amaranth or kañiwa) and content (20, 35 and $50 \%$ of tested flour) (Figure 1G'), and regressed towards the physical and sensory evaluation (i.e. TDS) of the same sample type and content (Figure 1H'). Thus, the analysis consisted of a total of nine samples and 134 wavelengths in the $\mathbf{X}$-matrix, and nine samples with 10 sensory attributes in Y. The NIR data was mean-centered and the sensory evaluation was autoscaled prior to the PLS model. No validation was performed, as the result only was interesting from an exploratory approach.

\section{RESULTS AND DISCUSSION}

Overview PCA

As a first step in the data analysis, a PCA was made on the 79 average spectra across each image. Instead of showing the score-plot with the 79 samples, 9 ellipses based on the average and standard error of each group (type and content of tested grains) are shown in Figure 2. The first component explains $82.1 \%$ of the variance, while the second component explains $10.1 \%$. It is evident that the chemical composition of samples containing kañiwa is very different from those containing amaranth and quinoa. Differences can be seen through PC1 (Figure 2A) and the loading plot (dotted line in Figure 2B). This is primarily due to a large peak at the very beginning of the spectra - with a probable maximum around $990 \mathrm{~nm}$ - caused by fibre. As shown in Table 1, kañiwa has a markedly larger fibre content than the other grains. However, as both this peak, and the peak at $1373 \mathrm{~nm}$ can be assigned to fibre, it is believed that not only the content of fibre, but also the composition of fibre in kañiwa is different from the other two grains. Fibre in kañiwa appears to be 
$\mathrm{nm}$, indicating changes in the protein composition between the samples. In general, samples with low content of kañiwa behave very similar to those with high content of amaranth and quinoa.

\section{NIR hyperspectral imaging of extrudates}

NIR images showed various score distribution patterns across extrudate samples (Figure 3). As noticed from Figure 2A, the samples containing kañiwa have clearly higher scores on PC1 than those containing amaranth and quinoa. Score-images with larger red sections seem to follow the content of fibre (Figure 3, PC1); this is particularly noticeable in samples containing kañiwa.

Score-images of samples containing amaranth and quinoa showed remarkable similarities for PC1. 20A and 20Q are almost undistinguishable, but differences become more evident at higher levels of grain incorporation (Figure 3, PC1). Samples containing quinoa presented slightly higher score values than the corresponding amaranth (see also Figure 2A). In general, the distribution of the scores for PC1 seems quite homogenous, with only minor changes within each image (Figure 3). This is very different for the score-images of $\mathrm{PC} 2$, where samples show random peaks of score distribution across individual images. Inevitably, the score positioning in Figure $\mathbf{2 A}$ is linked to the score images in Figure 3. From this one can observe the similarity among 20K, 35A, 50A and 50Q in terms of score distribution (i.e. large dark blue areas and few red ones). On the other hand, 20Q, 35Q, and 20A have similar average score values for PC2 (Figure 2A) but the score distribution was found to be quite different (Figure 3,PC2). For instance, 20A showed a high degree of heterogeneity with sharp and small red spots while 20Q and 35Q, though heterogenous, displayed smooth and large red areas (neighbouring pixels have similar values). Various authors have found that, in native amaranth and quinoa, starch and protein form strong links that require enzymatic treatment or alkali conditions to break them apart (Radosavljevic et al., 1998; Choi et al., 2004; Villarreal et al., 2013; Kumar et al., 2013). Probably, this makes more feasible for starch and protein to form intertwined matrices upon extrusion, like in extrudates containing amaranth (Figure 
2). The resulting molecular arrangement may strongly depend on the type of starch (e.g. amylose/amylopectin ratio) and protein (i.e. albumin, globulin, glutelin, prolamin) present in the flour mixture.

According to Cabrera-Chavez et al. (2012), insoluble native starch granules may have the capacity of entrap proteins during the gelatinization and retrogradation of amaranth starch. In the present study, the extrusion temperatures $\left(90-140{ }^{\circ} \mathrm{C}\right)$ were high enough to ensure a high degree of gelatinization, dextrinization and eventual retrogradation. In Figure 2B, the spectra show overtones at around $1470 \mathrm{~nm}(\max )$ and $1533 \mathrm{~nm}(\min )$, corresponding to the spectral features of starch retrogradation (Osborne, 1996). Generally, polysaccharide hydroxyl groups are exposed during extrusion contributing, most possibly, to the formation of links with other food polymers (Osborne, 1996). The cysteine residues present in glutelins (around $40 \%$ of total protein in amaranth; Bressani and Garcia-Vela, 1990) could have increased the content of thiols (-SH) thereby boosting the formation of protein-starch networks. Unfortunately, the overtone corresponding to thiols is commonly shown at $1740 \mathrm{~nm}$, beyond the boundaries of the wavelength range (1000-1700 nm) of the present study. Cabrera-Chavez et al. (2012) explained that the starch-protein network might rely on a combination of covalent (disulphide bonding) and non-covalent hydrophobic interaction.

Generally, quinoa and kañiwa have distinctively greater content of albumins and globulins than amaranth (Ramos Diaz, 2015), reaching, in some cases, almost $80 \%$ of the protein content (Romero, 1981). In addition, the ratio of amylopectin/amylose in amaranth starch is commonly higher than in quinoa starch (Qian and Kuhn, 1999). These differences could clearly affect the formation/stability of a starch-protein network upon extrusion.

\section{Combining NIR images with physical and TDS data}

The PLS model (Figure 4) made by combining NIR images (independent variables) with physical and TDS data (response variables) showed an extremely similar loading plot to the one in Figure 
2A. The correlations between the loadings from PLS and PCA are higher than 0.95, indicating that the same profile that applies to the description of the sensory attributes, applies to the chemical data. The only difference is that the sucrose/ starch peak at $1441 \mathrm{~nm}$ is larger for the PLS model, changing from a shoulder in the PCA to two peaks, with the protein peak at $1470 \mathrm{~nm}$ (results not shown).

PLS modelling allow the introduction of a cause-effect relationship between score distribution (Figure 3) and physical/TDS data (Table 2). As explained earlier, the score distribution in PC1 is associated to the content of fibre and, in the PLS context, fibre presents an inverse effect on roughness (Figure 2; Figure 4). Besides, 20K, 35A, 50A and 50Q presented very similar patterns of score distribution, visually characterized for having small red dots (associated to protein) spread across those samples (Figure 3B). These evenly-distributed protein-associated structures had a direct effect on crunchiness and crispiness, with some minor effect on gooeyness, stiffness, stickiness and SEI (Figure 4). In contrast, score distribution in 20A, 20Q and 35Q was visually characterized for having large and well-defined red areas (associated to protein). The unevenness of protein distribution as well as the formation of large protein clumps had a direct effect on roughness and hardness, and minor effects on WSI and WAI (Figure 4).

Although sensory profiling was initially included in the modelling, it had to be omitted due to technical challenges in the development of a reliable model. Apparently changes in the chemical data arising from NIR spectral data can be successfully reflected on sensory continuum attributes (e.g. TDS) rather than on mainstream sensory profiling. Details on the statistical analysis and level of significance associated to sensory data is comprehensively described by Ramos-Diaz et al. (2015). 
313 The increase of amaranth, quinoa and kañiwa had a considerable effect on the physical attributes of 314 corn-based extrudates as seen in Figure 4 and detailed in Table 2. Samples containing more fibre 315 and protein presented statistically lower SEI $(20 / 35 / 50 \mathrm{~A}, \mathrm{p}=0.0001 ; 20 / 35 / 50 \mathrm{Q}, \mathrm{p}=0.005$; 20/35/50K, p = 0.0001), WAI (20/35/50A, p=0.0001;20/35/50Q, p=0.004;20/35/50K, p = $0.039)$ and WSI (20/35/50A, $\mathrm{p}=0.007 ; 20 / 35 / 50 \mathrm{Q}, \mathrm{p}=0.0001 ; 20 / 35 / 50 \mathrm{~K}, \mathrm{p}=0.004)$. It was observed that the progressive increase of kañiwa led to the formation of protein clumps (Figure 2), possibly linked to the disruption of porous structures and reduction of sectional expansion. The incorporation of kañiwa reduced SEI by almost 50\% (50K, Table 2). In contrast, the sectional expansion of extrudates containing quinoa and amaranth (Figure 4) was not substantially reduced. In this case, the formation of protein clumps took place at low grain incorporation (e.g. 20A, 35A, 20Q) and eventually dispersed (e.g. 50A, 50Q).

The increase of amaranth, quinoa and kañiwa reduced the extrudates capacity to absorb and solubilize in water, probably, attributed to the formation of protein clumps. However, the effect was not the same for all grain types (Figure 4). Extrudates containing kañiwa were able to absorb more water (highest WAI), and were less likely to solubilize in water (lowest WSI) compared to those containing quinoa and amaranth. This might indicate presence of hydrophilic polymeric structures, possibly involving starch/fibre (Figure 2; Figure 3A). In contrast, extrudates containing amaranth were the least able to absorb water (lowest WAI) and the most likely to solubilize (highest WSI). Interestingly, protein clumps were not clearly observed in extrudates containing amaranth (Figure 3B). It is likely that the formation of protein aggregates and/or starch-protein complexes (clumps observed as large red areas) stabilize the structure of the system, thereby allowing it to absorb water and preventing further solubilisation. Due to the high standard deviation of stiffness, only minor changes among tested samples were observed (Table 2). Extrudates containing more amaranth 
became structurally weaker $(20 / 35 / 50 \mathrm{~A}, \mathrm{p}=0.001)$, which seems consistent with low WAI and high WSI if compared with other tested samples (Table 2).

\section{CONCLUSIONS}

This study shows that the chemical profile obtained through NIR hyperspectral imaging can be successfully linked to specific sensory and (to a lesser extent) physical attributes. Changes in spectral data was accurately reflected in temporal dominance of sensations (TDS) rather than in sensory profiling. Appealing TDS attributes such as crunchiness and crispiness were linked to evenly distributed protein-associated structures while undesirable roughness was clearly linked to the formation of protein clumps (e.g. protein aggregates, protein-starch complexes). In the present study, increasing content of fibre was found to reduce the sensation of roughness. The versatility of NIR to monitor food properties at industrial scale is well known, but its ability to predict textural attributes is much lesser known. This study proves that fast-monitoring techniques could be used to analyse the textural quality of extruded snacks.

\section{ACKNOWLEDGEMENTS}

Authors thank the European Cooperation of Science and Technology (COST) Action FA1001 for supporting this research through a Short Term Scientific Mission (STSM) at University of Copenhagen in Denmark. 


\section{REFERENCES}

Alander, J.T., Bochko, V., Martinkauppi, B., Saranwong, S., \& Mantere, T. (2013). A review of optical nondestructive visual and near-infrared methods for food quality and safety. International Journal of Spectroscopy, 2013, 1-36.

Bhargava, A., Shukla, S., \& Ohri, D. (2006). Chenopodium quinoa - An Indian perspective. Industrial Crops and Products, 23, 73-87.

Babin, P., Della Valle, G., Dendievel, R., Lourdin, D., Salvo, L. (2007). X-ray tomography study of the celular structure of extruded starches and its relations with expansion phenomenon and foam mechanical properties. Carbohydrate Polymers, 68, 329-340.

Bressani, R., \& García-Vela, L.A. (1990). Protein fractions in amaranth grain and their chemical characterization. Journal of Agriculture and Food Chemistry, 38, 1205-1209.

Cabrera-Chavez, F., Calderon de la Barca, A.M., Islas-Rubio, A.R., Marti, A., Marengo, M., Ambrogina Pagina, M., Bonomi, F., \& Lametti, S. (2012). Molecular rearrangements in extrusion processes for the production of amaranth-enriched, gluten-free rice pasta. LWT-Food Science and Technology, 47, 421-426

Choi, H., Kim, W., \& Shin, M. (2004). Properties of korean amaranth starch compared to waxy millet and waxy sorghum starches. Starch/Stärke, 56, 469-477. 
FAO (2011). Quinoa: An ancient crop to contribute to world food security. Regional office for

Latin America and Caribbean. http://www.fao.org/docrep/017/aq287e/aq287e.pdf / Accessed 25 May 2018.

Geladi, P., MacDougall, D., \& Martens, H. (1985). Linearization and Scatter-Correction for Near-Infrared Reflectance Spectra of Meat. Applied Spectroscopy, 39, 491-500.

Jacobsen, S.-E. (2003). The worldwide potential for quinoa. Food Review International, 19, 167-177.

394

Janick, J., M.G. Blase, D.L. Johnson, G.D. Jolliff, \& R.L. Myers. (1996). Diversifying U.S. crop production. In: J. Janick (ed.), Progress in new crops (p. 98-109). Alexandria, VA: ASHS Press.

400 
Lindeboom, N. (2005). Studies on the characterization, biosynthesis and isolation of starch and protein from quinoa (Chenopodium Quinoa WILD). Doctoral dissertation. Canada: University of Saskatchewan.

Lorenz, K. (1990). Quinoa (Chenopodium quinoa) starch: Physico-chemical properties and functional characteristics. Starch/Stärke, 42, 81-86. processed cereal foods. Journal of Near Infrared Spectroscopy, 4, 195-200.

Qian, J.Y., \& Khun, M. (1999). Characterization of Amaranthus cruentus and Chenopodium quinoa starch. Starch/Stärke, 51, 116-120. alkaline-protease treatment. Cereal Chemistry, 75, 212-216.

Ramos-Diaz, J.M. (2015). Use of amaranth, quinoa, kañiwa and lupine for the development of gluten-free extruded snacks. Doctoral dissertation. Finland: University of Helsinki. Jouppila, K.. (2013). Use of amaranth, quinoa and kañiwa in extruded corn-based snacks. Journal of Cereal Science, 58, 59-67. 
based snacks containing amaranth and quinoa: Application of Partial Least Squares Regression. Journal of Food Process Engineering, 40, e12320.

432

Ramos-Diaz, J.M., Suuronen, J.-P., Deegan, K.C., Serimaa, R., Tuorila, H., Jouppila, K. (2015). Physical and sensory characteristics of corn-based extruded snacks containing amaranth, quinoa and kañiwa flour. LWT-Food Science and Technology, 64, 1047-1056.

Romero, J.A. (1981). Evaluacion de las caracteristicas fisicas, quimicas y biologicas de ocho variedades de quinoa (Chenopodium quinoa Willd.). Master's thesis. Guatemala: Universidad de San Carlos de Guatemala.

Savitzky, A, \& Golay, M. (1964). Smoothing and differentiation of data by simplified least squares procedures, Analytical Chemistry, 36, 1627-1639.

Scarpati de Briceño, Z. (1979). Aislamiento y caracterizacion de almidon de quinua (Chenopodium quinoa) y canihua (Chenopodium pallidicaule). Conference paper at the National Congress in Food Science and Technology, Universidad Nacional Agraria, Lima, Peru. nutricional de algunas entradas de quinua (Chenopodium quinoa Willd.) del banco de germoplasma de la Universidad Tecnica del Altiplano. Annales Cientifico, 18, 125-143. 
455 Villarreal, M. E., Ribotta P. D., \& Iturriaga, L. B. (2013). Comparing methods for extracting 456 amaranthus starch and the properties of the isolated starches. LWT - Food Science and 457 Technology, 51, 441-447.

458

459

460

461

462

463

464

465

466

467

468

469

470

471

472

473

474 


\section{TABLES}

476 Table 1. Content of protein and fibre in amaranth, quinoa, kañiwa and corn flours. The calculated

477 contents for flour blends were also included (Ramos-Diaz, 2015).

478

\begin{tabular}{ccc}
\hline & \multicolumn{2}{c}{ Content (\% of solids) } \\
\cline { 2 - 3 } & Protein & Fibre \\
\hline Amaranth (A) & 16.1 & 8.3 \\
20A : 80C & 9.8 & 6.3 \\
50A : 50C & 12.2 & 7.1 \\
Quinoa (Q) & 13.1 & 9.1 \\
20Q : 80C & 9.2 & 6.5 \\
$\mathbf{5 0 Q}: \mathbf{5 0 C}$ & 10.7 & 7.5 \\
Kañiwa (K) & 16.7 & 16.1 \\
$\mathbf{2 0 K}: \mathbf{8 0 C}$ & 9.9 & 7.9 \\
$\mathbf{5 0 K}: \mathbf{5 0 C}$ & 12.5 & 11 \\
Corn $(\mathbf{C})$ & 8.2 & 5.8 \\
\hline
\end{tabular}


Table 2. Physical/physicochemical and sensory characteristics of corn-based extruded snacks containing 20, 35 and 50\% amaranth (A), quinoa (Q) and 481 kañiwa (K). The data were obtained from Ramos-Diaz et al. (2015) and Ramos-Diaz (2015).

\begin{tabular}{|c|c|c|c|c|c|c|c|c|c|c|c|c|c|c|}
\hline & \multicolumn{4}{|c|}{ Physical/Physicochemical properties* } & \multicolumn{4}{|c|}{ Sensory profiling** } & \multicolumn{6}{|c|}{ Temporal studies $\left(\mathrm{cm}^{2}\right)^{* * *}$} \\
\hline & SEI & STF, N/mm & WAI, \% d.b. & WSI, \% d.b. & CRISP & HARD & HARD_P & ADHE & CRISP & CRUN & HARD & STICK & ROUGH & GOO \\
\hline 20A & $11 \pm 1 \mathrm{a}$ & $45.9 \pm 11.2 \mathrm{a}$ & $387.1 \pm 8.3 \mathrm{a}$ & $35.2 \pm 1.1 \mathrm{a}$ & $9.0 \pm 0.1$ & $5.6 \pm 0.3$ & $5 \pm 0.4$ & $7 \pm 0.3$ & 14.4 & 27.0 & 12.6 & 41.3 & 28.8 & 24.1 \\
\hline 35A & $11.2 \pm 1 \mathrm{a}$ & $28.1 \pm 9.4 \mathrm{~b}$ & $354.9 \pm 3.3 \mathrm{~b}$ & $34.1 \pm 0.3 \mathrm{a}$ & $8.0 \pm 0.2$ & $3.3 \pm 0.3$ & $1.5 \pm 0.2$ & $5.3 \pm 0.3$ & 17.2 & 37.6 & 7.3 & 40.1 & 15.5 & 31.4 \\
\hline 50A & $8.7 \pm 0.5 \mathrm{~b}$ & $22.5 \pm 4.5 b$ & $322.3 \pm 5.8 \mathrm{c}$ & $32.1 \pm 0.6 \mathrm{~b}$ & $7.7 \pm 0.2$ & $3.5 \pm 0.5$ & $1.3 \pm 0.3$ & $6.5 \pm 0.3$ & 21.3 & 44.0 & 7.3 & 43.3 & 7.7 & 43.5 \\
\hline $20 Q$ & $9.9 \pm 0.9 \mathrm{a}$ & $32.0 \pm 10.9 \mathrm{a}$ & $400.4 \pm 2.0 \mathrm{a}$ & $32.6 \pm 0.6 \mathrm{a}$ & $8.3 \pm 0.1$ & $5 \pm 0.6$ & $7.7 \pm 0.2$ & $6.6 \pm 0.4$ & 16.5 & 23.8 & 17.5 & 34.7 & 38.4 & 19.0 \\
\hline $35 Q$ & $11.0 \pm 0.7 \mathrm{a}$ & $24.0 \pm 8.8 \mathrm{a}$ & $408.1 \pm 1.5 b$ & $28.0 \pm 0.04 \mathrm{~b}$ & $8.4 \pm 0.2$ & $4.0 \pm 0.4$ & $5.4 \pm 0.3$ & $5.9 \pm 0.3$ & 19.8 & 29.6 & 9.4 & 36.4 & 32.6 & 24.9 \\
\hline $50 Q$ & $9.8 \pm 0.8 \mathrm{a}$ & $37.7 \pm 15.8 \mathrm{a}$ & $399.2 \pm 2.5 \mathrm{a}$ & $21.1 \pm 2.7 \mathrm{c}$ & $7.9 \pm 0.2$ & $2.6 \pm 0.3$ & $1.9 \pm 0.3$ & $4.8 \pm 0.3$ & 20.2 & 51.3 & 6.5 & 34.9 & 11.8 & 26.1 \\
\hline $20 K$ & $10.1 \pm 1.1 \mathrm{a}$ & $52.3 \pm 21 \mathrm{a}$ & $427.0 \pm 12.4 \mathrm{a}$ & $26.6 \pm 1.4 \mathrm{~b}$ & $8.5 \pm 0.1$ & $4.1 \pm 0.3$ & $1.7 \pm 0.3$ & $4.6 \pm 0.4$ & 16.4 & 47.3 & 8.8 & 34.4 & 11.6 & 30.4 \\
\hline $35 K$ & $8.2 \pm 1.1 \mathrm{~b}$ & $30.9 \pm 17.5 \mathrm{a}$ & $413.4 \pm 4.5 \mathrm{a}$ & $26.6 \pm 0.5 \mathrm{a}$ & $7.4 \pm 0.2$ & $5.5 \pm 0.3$ & $1.6 \pm 0.3$ & $4.8 \pm 0.4$ & 15.3 & 34.7 & 22.7 & 33.9 & 6.6 & 34.3 \\
\hline $50 \mathrm{~K}$ & $5.4 \pm 1.1 \mathrm{c}$ & $34.6 \pm 10.6 \mathrm{a}$ & $405.2 \pm 3.4 \mathrm{~b}$ & $23.2 \pm 0.2 \mathrm{~b}$ & $5.7 \pm 0.3$ & $7.1 \pm 0.4$ & $1.5 \pm 0.3$ & $4.7 \pm 0.4$ & 12.9 & 45.8 & 17.9 & 33.1 & 5.2 & 34.7 \\
\hline
\end{tabular}

482 *SEI, sectional expansion index; STF, stiffness; WAI, water absorption index; WSI, water solubility index. *Different letters (a, b, c) within the same category

483 indicate significant difference at $\mathrm{p}<0.05$.

$484 * *$ CRISP, crispiness; HARD, hardness; HARD_P, hard particles; ADHE, adhesiveness. Deviation expressed by standard error of the mean. 
Figure 3. Score images corresponding to the first two PCs of one sample. Images were sorted following the type and amount of tested grains. The image was selected as to show the average tendencies. The two bars show the scale for the score-values used for the images.

Figure 4. The bi-plot of the PLS model showing the samples (crosses; grey scale according to grain type) and the physical/physicochemical (red circle) and TDS data (thick-lined red circles). Samples: 20/35/50A (cornbased extruded samples containing 20, 35 or 50\% amaranth of solids); 20/35/50Q (corn-based extruded samples containing 20, 35 or 50\% quinoa of solids); 20/35/50K (corn-based extruded samples containing 20, 35 or $50 \%$ kañiwa of solids). Physical/physicochemical characteristics: SEI (sectional expansion index); STF (stiffness); WAI (water absorption index); WSI (water solubility index). TDS attributes: CRIP (crispiness); HARD (hardness); HARD, (hardness); STICK (stickiness); ROUGH (roughness); GOO (gooeyness). 


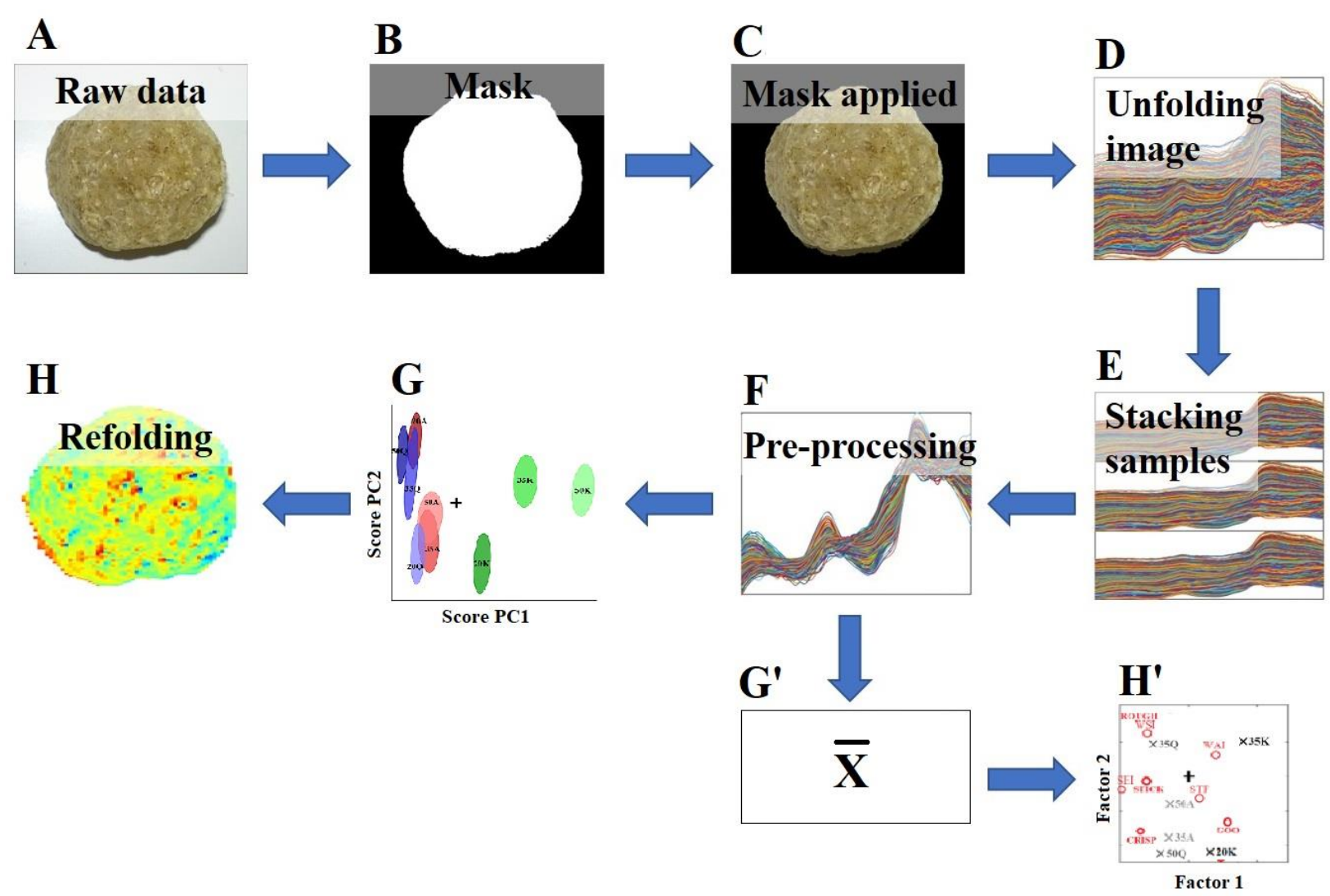


A

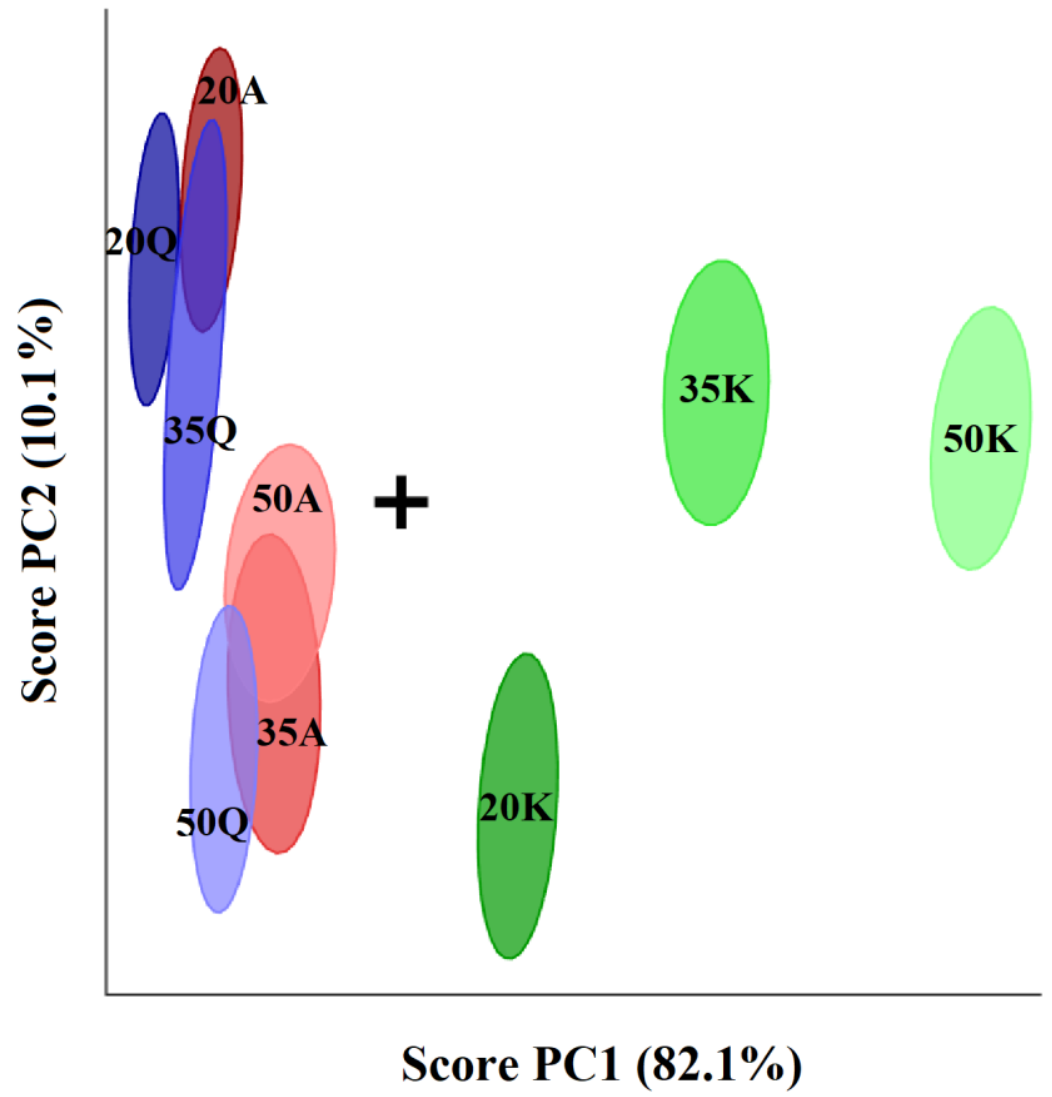

B

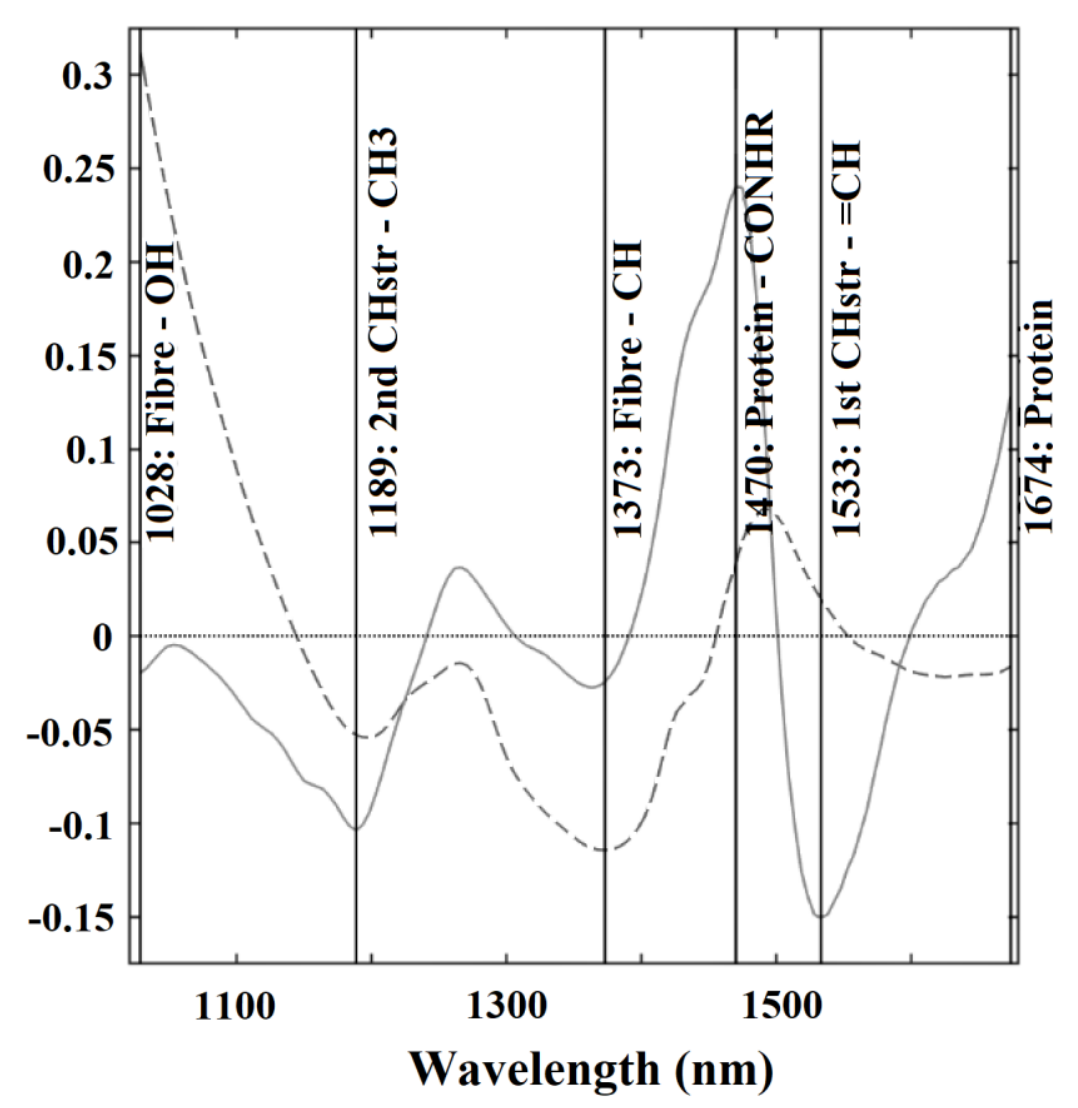


Figure 3

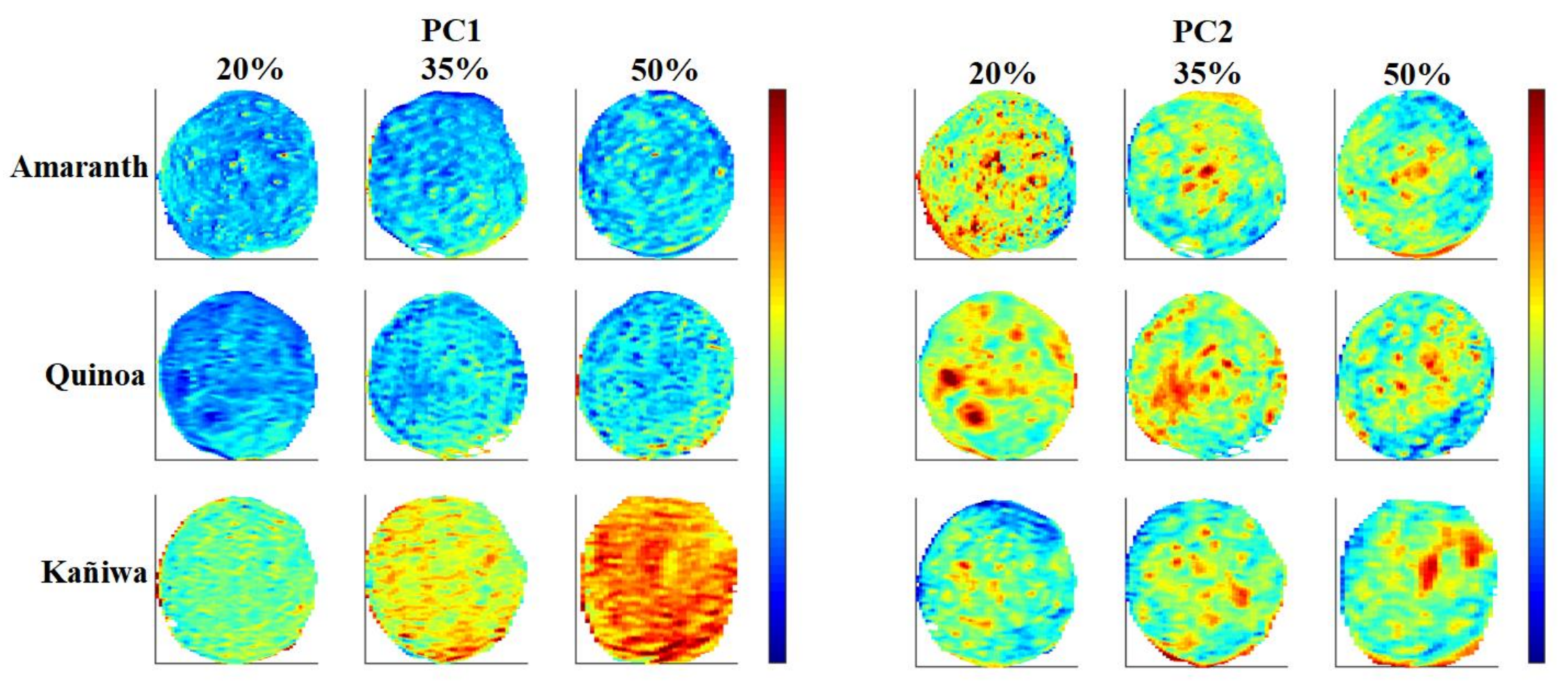




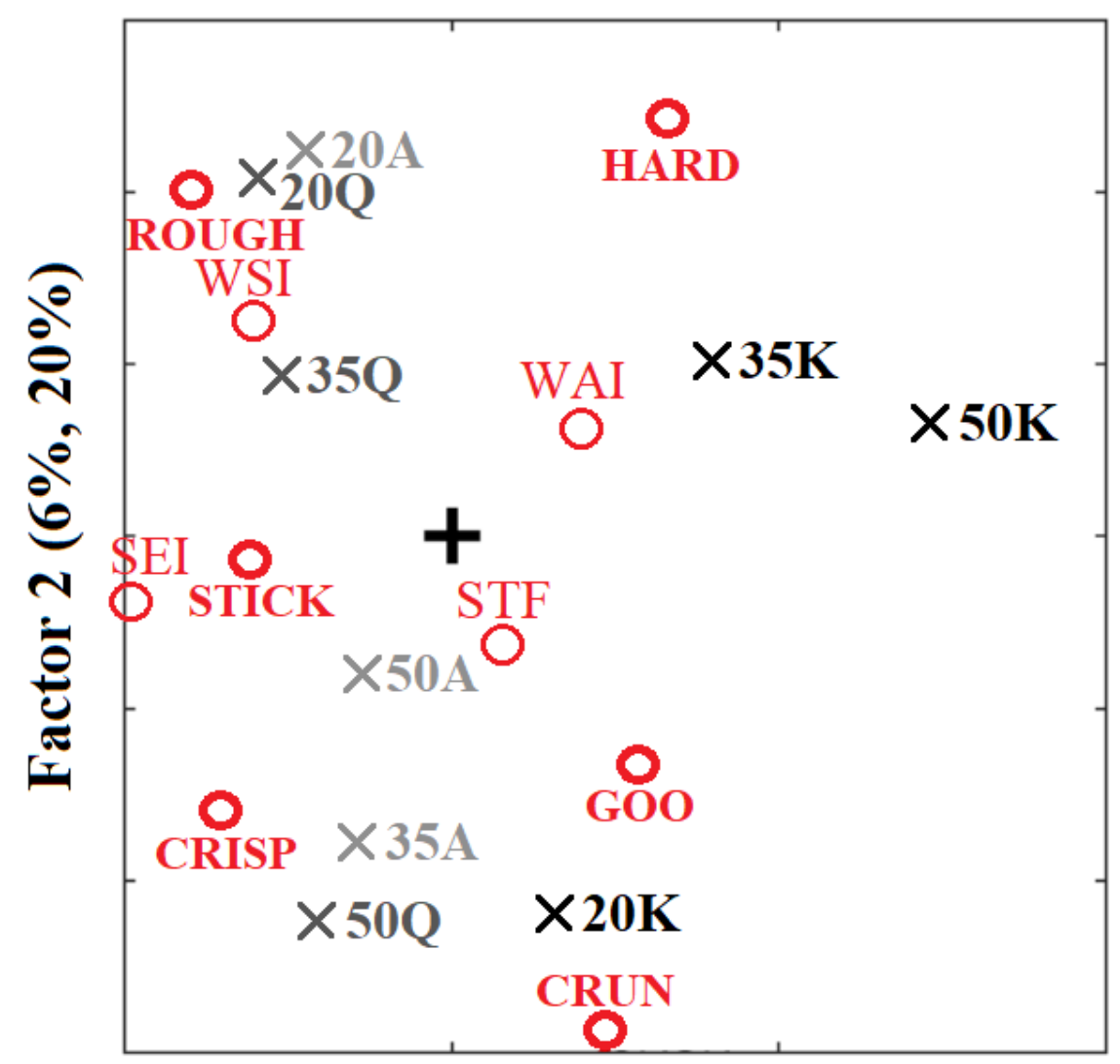

Factor $1(92 \%, 30 \%)$ 